steadily. A somewhat similar distortion, though less pronounced, occurs in early October, when the curve for 1901-29 shows a definite slackening of the autumn fall of temperature.

The third point of interest concerns the temperatures of high summer. Both curves show a marked swing, with a range of $2^{\circ} \mathrm{F}$., from a maximum in mid-July to a minimum early in August and back to a second maximum in mid-August. This feature was of such interest that the five-day means of temperature at Greenwich during July and August were extracted for the period 18411865, and are shown in the upper inset of Fig. 1. Here the July maximum is again shown, but the minimum early in August does not appear and the August maximum is reduced to very small proportions. The impression left by a comparison of these three curves is that there is a definite tendency for a warm spell to occur in mid-July, after which there is a period during which temperature oscillates irregularly until the autumn fall sets in after the middle of August.

Although the comparison of curves showing averages over a number of years is the simplest method of approaching a problem of this nature, the results are sometimes misleading. The more interesting abnormalities revealed by Fig. 1 were accordingly studied year by year, in order to determine whether they are regular characteristics of the climate or whether they merely reflect a few outstanding events. In the first place the "Buchan cold spells ' in February, April, and May were examined to determine if there was any definite tendency for temperature in individual years to fall to minima on those dates. The results were entirely negative; the chance that one of these periods will be unseasonably cold is exactly equal to the chance that it will be unseasonably warm. If we allow a 'grace' of two days on either side, the individual curves show that temperature actually rose to a maximum more often than it fell to a minimum.

The warm period in mid-July affords an example of the fallacy sometimes introduced by reasoning from averages. During the whole 59 years the average temperature was highest on July 15-19, but when the individual years were examined, this predominance was found to rest entirely on four years, 1876, 1881, 1900, and 1921, while temperature was below the smooth curve on 30 occasions out of the remaining 55. The second crest on the curve occurs on August 14-18, and this period was abnormally warm on 32 occasions, cool on 27, a negligible difference.

The general conclusions drawn from the investigation were summed up as follows: "On the whole it seems improbable that there exists in our climate an abiding tendency for any part of the year to be either abnormally warm or abnormally cold for the season. It does seem, however, that such tendencies may spring up suddenly, persist for ten or twenty or thirty years, and as suddenly and mysteriously vanish. Any positive conclusions as to these spells are valid only for the time and place of their occurrence, and cannot be applied to other times or places. Thus, while Buchan's cold and warm spells were probably true for Scotland in the 1860's, they are certainly not true for London in the twentieth century.",

In the discussion which followed the paper, Mr. D. Brunt objected that 'cold spells' were on some occasions limited to one or two days, and these would be masked by the use of five-day means. $\mathrm{He}$ also thought that the investigation should have dealt with individual years rather than with averages over long periods. It was suggested that a possible explanation of the persistent belief in Buchan's cold and warm spells was that when they did occur, they had a tendency to fall on or near Buchan's dates, though in many years they were absent. On the other hand, Mr. Mirrlees thought that the belief had persisted because meteorologists had devoted a great deal of effort to explaining the occurrence of such spells, and little or none to finding out whether there was anything to explain. Apart from this, a few of the explanations advanced were sufficiently plausible, for example, pressure changes set up by differential warming of the earth's surface, and outbreaks of polar ice, but as usually happens when theorising loses touch with facts, some of the theories were merely absurd. They included cosmic dust from meteor showers in the earth's atmosphere, cometary matter between the earth and the sun, the latent heat of freezing and thawing of Russian rivers, the varying absorption of radiation owing to changes of humidity, and mirabile dictu, the meteorological effects of newly expanded foliage in spring.

C. E. P. Brooks.

\title{
Crime Statistics of England and Wales.
}

CRIMINAL statistics, apart from their primary purpose, usually afford some interesting sidelights on social habits and in particular on any changes which are taking place in the daily life of the community with which they deal. For example, in the criminal statistics of England and Wales for the year 1928 (Cmd. 3581, H.M. Stationery Office, price $4 s$. net) an attempt has been made to gauge the effect of the coming of the 'motor age" on crime. Taking the year 1928 and comparing the figures for the crime of 'breaking in' with those of 1911 it appears that, while the figures for the metropolitan area are practically stationary, in the home counties they show an increase of 437.8 per cent, and over the whole of England and Wales outside the metropolitan area the increase in boroughs and cities is 87 per cent, but in the counties it is 137 per cent. This is attributed to the increased use of the motor-car, which is thought to have acted in two ways. Greater numbers of the population have been enabled to live outside urban areas and premises are more often left unoccupied, while an increase in the ' all in' policy of insurance has tended to reduce precaution. On the other

No. 3167, VoL. 126] 
hand, the burglar is also able to avail himself of the car and thus to travel with greater speed and further afield.

A preliminary analysis of the crime statistics in the return contains some interesting remarks relating to variations in the character and volume of crime. The quinquennium 1910 to 1914 is taken as a basis of comparison, as representing a normal average of criminality. Since this period the rise in population has been $9 \cdot 26$ per cent, and the normal rise in crime is therefore taken to be round about 9 per cent. Only figures over this percentage are taken as indicative of any real increase in crime. It may be noted in passing that both in the years after the Boer War and after the Great War there was a marked increase in criminality.

Taking the principal classes of crime, that is, indictable offences, as a whole the figures of 1928 show an increase of 33 per cent over those of 1910 1914. The highest increase in any individual class is under the head of offences against property with violence- 80 per cent-while crime against the person increases by 22 per cent. Malicious injury to property falls by 57 per cent. But to bring out the significance of these figures a further analysis is necessary. Taking the class of offences against the person, these fall into two categories-sexual offences and offences generally of violence against the person. In the latter, after making allowance for the rise of 9 per cent, the only offence that shows an appreciable rise is that of procuring abortion. Such crimes as murder and attempts to murder, manslaughter, cruelty to children and child-stealing are among those that show a decrease. The net decrease over all is 4 per cent. In sexual crimes the greatest increase is in indecent assault and defilement of girls between 13 and 16 . In the case of rape, defilement of very young girls, and in procuration and abduction there are decreases. Bigamy showed a very high figure-an increase of 120 per cent; but there is a decrease as compared with the period 1920-24. Offences between males increased.

In the class which shows the next greatest increase over 1910-14-crime against property with violence-a heavy increase in offences of 'breaking in', attempts at entering and being in possession of housebreaking tools far outweighs decreases in burglary and robbery. Reference has already been made to the motor-car as a factor in this section of crimes. It is to be noted in this connexion and also in connexion with certain other classes of crime, that the increase is in part due to the fact that a number of cases previously unreported are now brought to the notice of the police. For this the increase of insurance is to some extent responsible as such casès are now reported in order to obtain compensation.

Some interesting points are raised in an attempt to ascertain how far crime is affected by certain social factors, such as education, improved social conditions, and the old age pension, the after effects of war service, and the increased activity of women.

For the purpose of investigating the bearing of education on crime, the figures of 1928 are compared with those of 1882 , when the results of the
Education Acts of the 'seventies were beginning to bear fruit. It is sometimes said that the criminal now works with brains not brawn; but the figures in those classes of crime in which education is the primary requisite scarcely seem to bear this out. Since 1882 the population has increased by 50 per cent, but the increase in indictable offences is 30 per cent only. The incidence in offences against the person was about the same, but malicious injury to property and forgery and currency offences, the most likely to be affected by education, showed a decrease of 46 per cent and 3 per cent respectively. On the other hand, larceny of post letters increased; but this was owing in part to the immense increase in the volume of correspondence and the greater number of people handling the mails. Frauds also show a heavy increase, but this is a matter of recent years, and up to 1900 the figures show little variation.

Significant facts emerge in an examination of male age groups which bears upon the question of the effects of war experience and social conditions. The opinion is frequently expressed that war experience has led to a disregard to the rights of property and a disposition among war service men to take whatever is wanted and whenever it is wanted. But as a matter of fact the age groups in 1928 of those men who passed through the War compare very favourably with their seniors and juniors except in respect of obtaining by false pretences, frauds, etc. The group 21-30, however, which during the war would have ranged in age from 7 to 16 , shows a relatively high rise in incidence of convictions and has obviously suffered from absence of parental control and other social conditions during the War. Again, the effect of improved social conditions and of the old age pension is seen in the older groups of 50 and over, where there is a fall in the incidence of convictions of 52 per cent.

As regards crime among women, the figures as a whole show that the increasing activities of women have not resulted in any serious rise in crime and have been accompanied by a great fall in the less serious and petty offences. Non-indictable offences have fallen 34.5 per cent, while the number of women has increased by 11 per cent. Cases of simple drunkenness have fallen from 12,219 to 5249 , and aggravated drunkenness from 26,045 to 5489 . Cases of eruelty to or neglect of children fell from 1424 to 362 .

The figures for non-indictable offences present certain points of considerable social interest and significance. While there is an increase in less serious offences under Customs, Excise, and Inland Revenue laws, and a huge increase in motoring offences, proceedings for all offences denoting criminality or debased conditions of life have fallen considerably.

Studied comparatively, the statistics as a whole tend to show a more orderly and law-abiding population, living in improved social conditions. The most serious problem they reveal, as indicated by the incidence of crime in the age-groups, is that of the care and training of the adolescent.

No. 3167, VoL. 126] 